'Departamento de Imágenes, Clínica Alemana de Santiago, Chile. ${ }^{2}$ Centro de Imagenología, Hospital Clínico Universidad de Chile, Chile.

${ }^{3}$ Departamento de Cirugía Mínimamente Invasiva, Clínica Alemana de Santiago. ${ }^{4}$ Servicio de Anatomía Patológica, Clínica Alemana, Facultad de Medicina Universidad del Desarrollo Santiago.

Recibido el 8 de abril de 2009, aceptado el 24 de mayo de 2010.

Correspondencia a: Dr. Claudio Cortés Arriagada. Departamento de Imágenes Clínica Alemana de Santiago E-mail: claudiocort@gmail.

\section{Pólipo fibrovascular esofágico. Estudio por imágenes multimodalidad}

\author{
CLAUDIO CORTÉS A. ${ }^{1,2}$, JUAN CARLOS DÍAZ P. ${ }^{1,2}$, \\ CLAUDIO NAVARRETE G. ${ }^{3}$, CECILIA CASTILLO ${ }^{3}$, \\ MARCELA GALLEGOS ${ }^{4}$, CLAUDIO SILVA F.-A. ${ }^{1}$
}

\section{Endoluminal excision of an esophageal fibrovascular polyp. Report of one case}

We report a 47 years old woman presenting with dysphagia. A chest CAT scan and barium swallow showed an endoluminal mass that extended to four vertebrae. An endoluminal sonography localized the pediculum of the mass, that was excised endoscopically. The pathological study disclosed a fibrovascular polyp. After 18 months of follow up, the patient is asymptomatic.

(Rev Med Chile 2010; 138: 742-745).

Key words: Deglutition disorders; Endoscopy, digestive system; Polyps.
L a disfagia es una entidad con una serie de causas, donde la dificultad del paso de los alimentos por el tracto digestivo superior puede estar determinado por causas mecánicas o motoras. El estudio por imágenes aporta información de localización, extensión y, en algunos casos, diagnóstico causal de éstos.

Ello se puede realizar a través de técnicas como los estudios baritados. Esta técnica nos permite, mediante la visualización de la ingesta de un medio de contraste radiopaco e inerte, evaluar en tiempo real los trastornos motores. La ventaja es que, además, podemos identificar lesiones parietales y endoluminales. Dentro del ámbito de las imágenes no invasivas, tenemos además la posibilidad de realizar estudios de tomografía multicorte, que nos da una excelente resolución de imagen, permitiendo un análisis además de las estructuras extraparietales.

El estudio endoscópico permite una imagen directa del lumen del tubo digestivo y, en algunos casos seleccionados y en manos entrenadas, poder obtener muestras histológicas. En los tiempos actuales existe incluso la posibilidad de lograr resolución de la patología por un enfrentamiento mínimamente invasivo.
Presentamos un caso inhabitual de disfagia, con sus imágenes características y diagnósticas, con una resolución novedosa y mínimamente invasiva, por vía endoscópica.

\section{Caso clínico}

Paciente de sexo femenino de 47 años, con historia de disfagia de meses de evolución. Se realizó endoscopía digestiva alta que mostró una masa intraesofágica elongada y ulcerada que se iniciaba a nivel del esfínter cricofaríngeo.

Se complementó estudio con tomografía computada de tórax que identificó dicha masa endoluminal, de predominio hipodenso en rango adiposo (Figura 1). El estudio baritado del esófago mostró una masa intraluminal de superficie lisa, e irregular en su extremo, que se extiendía en longitud por cuatro cuerpos vertebrales (Figura 2).

La endosonografía esofágica hizo evidente el componente vascular del pedículo (Figura 3). Se realizó endoscopía terapéutica en la que se enlazó el pólipo con un asa desde la porción distal (intraesofágica), realizando una tracción suave hacia la cavidad oral (Figura 4). Posteriormente se ligó el 

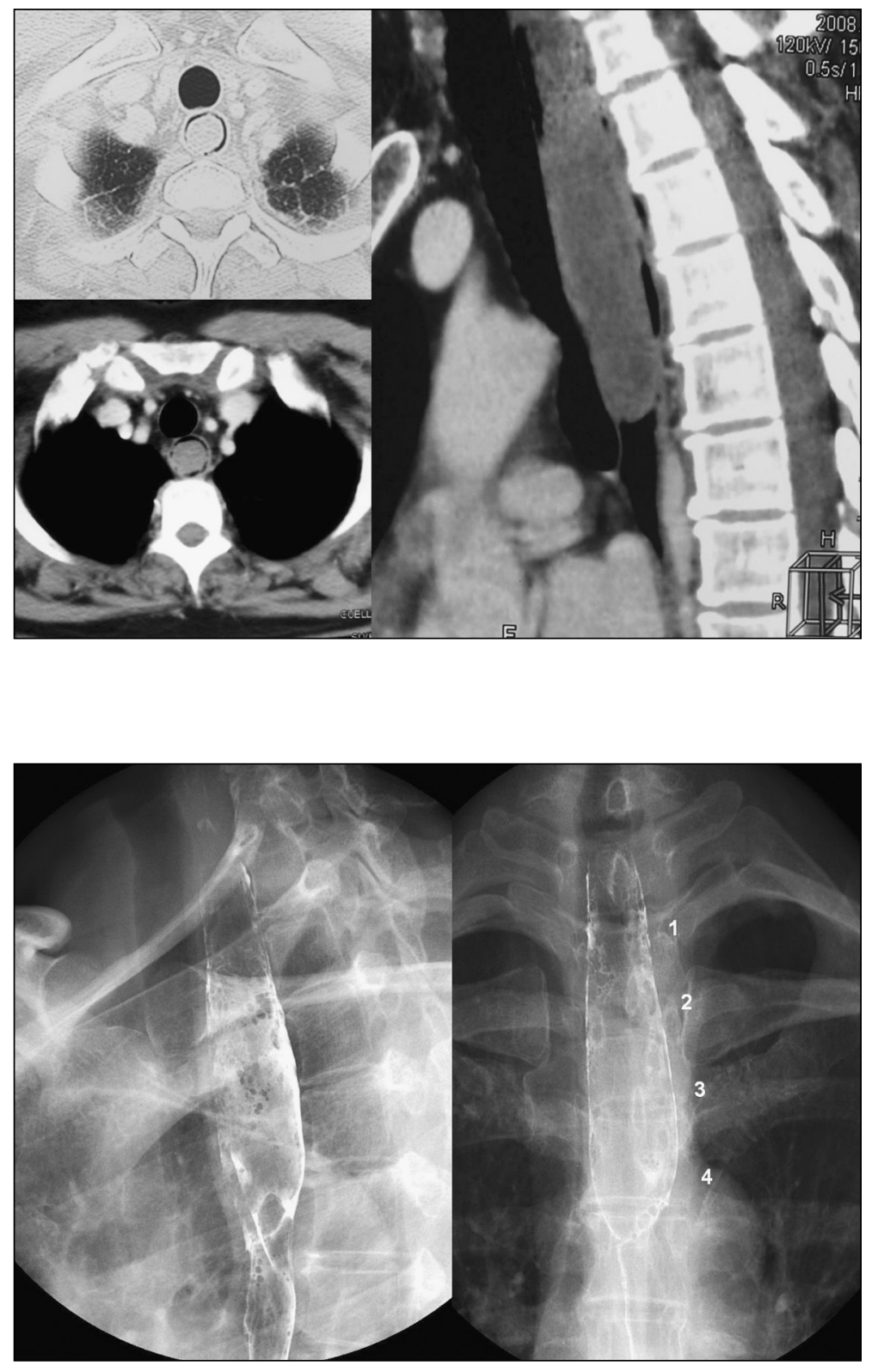

Figura 1. Tomografía computada de tórax, en ventana de pulmón y mediastino, y reconstrucción multiplanar en plano sagital.
Figura 2. Esofagograma baritado, que revela lesión intraluminal, con extremo ulcerado y una extensión de 4 cuerpos vertebrales. pedículo y se realizó resección de éste a nivel de su base (Figura 5). En la evaluación macroscópica de anatomía patológica, se evidenció que la longitud de este pólipo fue de $7 \mathrm{~cm}$ (Figura 6). El estudio histológico reveló un revestimiento constituido por epitelio escamoso no queratinizante con moderada acantosis, con un eje conectivo fibroso con numerosos vasos de tipo de tipo vénulo-capilar y venoso, algunos dilatados, proliferación de fibroblastos y leve infiltrado inflamatorio mixto (Figura 7). Estos hallazgos fueron compatibles con pólipo fibrovascular de la unión faringoesofágica.

La paciente evolucionó favorablemente, fue dada alta libre de sintomatología, y en los seguimientos clínicos y por imágenes realizados hasta 18 meses, persistió sin molestia alguna. 

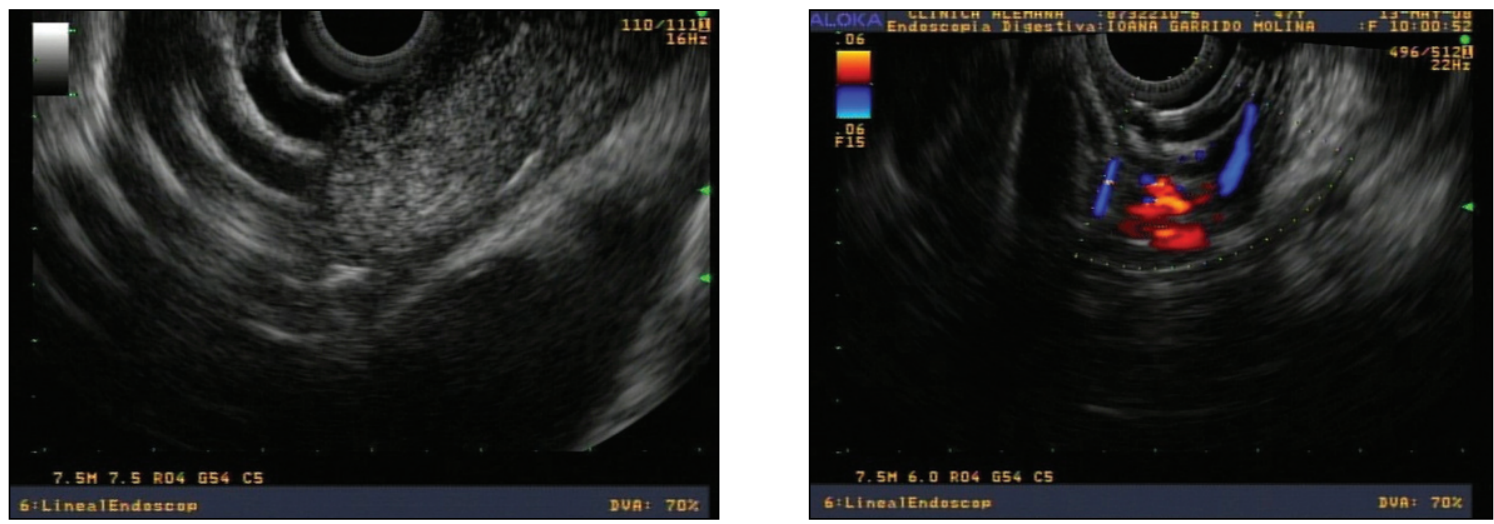

Figura 3. a: Visión endosonográfica de lesión endoluminal de ecogenicidad heterogénea, bien delimitada, con vascularización a la señal Doppler color (3 b).

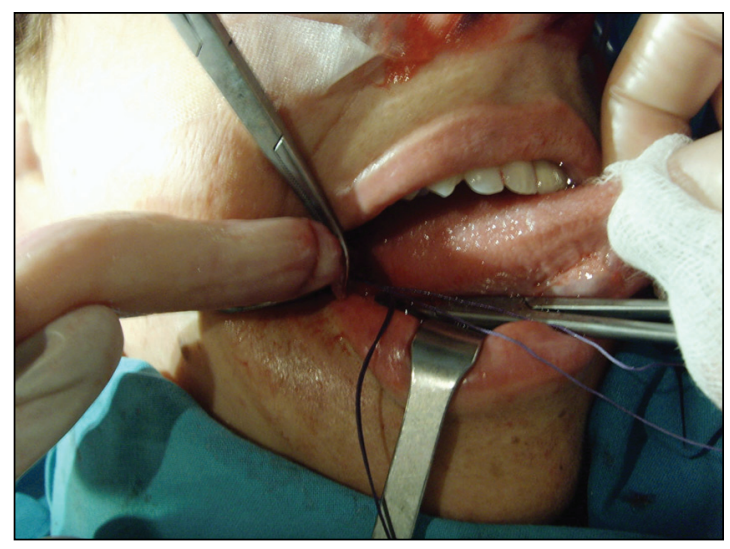

Figura 4. Extracción endoscópica.

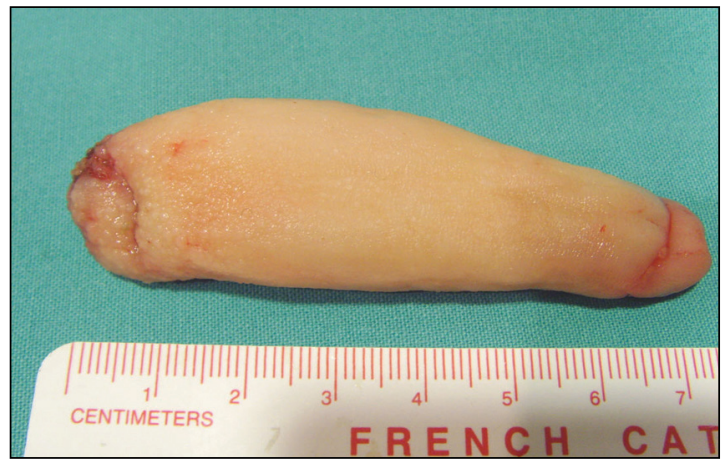

Figura 6. Visión macroscópica de pólipo resecado.

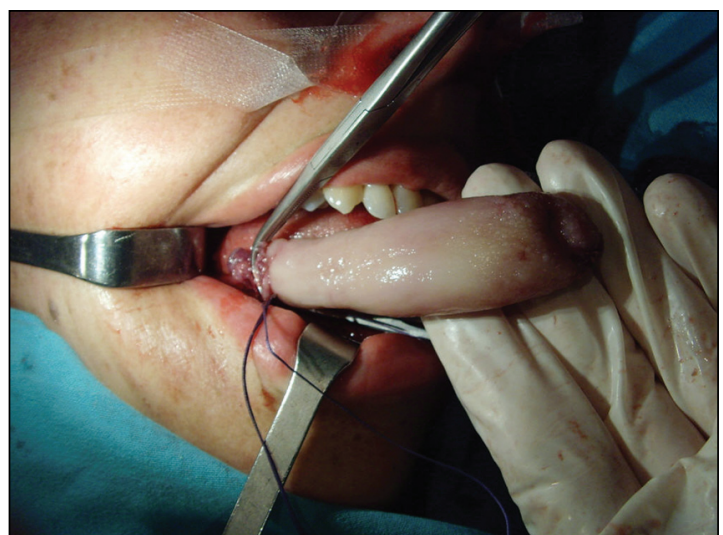

Figura 5. Extracción endoscópica.

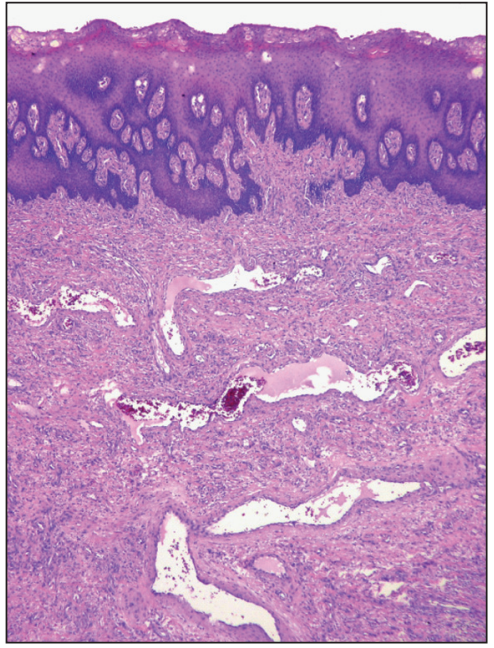

Figura 7. Histología a $40 x$ de pólipo que revela un eje fibrovascular, con revestimiento de epitelio escamoso no queratinizante. 


\section{Discusión}

El pólipo fibrovascular esofágico es un tumor de rara incidencia, intraluminal, que está compuesto de tejido fibroso, adiposo y estructuras vasculares $^{1-3}$. Son habitualmente pedunculados y se originan en el esófago cervical a nivel del cricofaríngeo ${ }^{3}$, pudiendo prolongarse por el lumen en forma paulatina hasta alcanzar el tercio medio o distal, e incluso hasta el estómago ${ }^{1}$.

Su sintomatología es vaga, siendo la disfagia el síntoma más frecuente, seguido por tos y estridor que se cree producto de compresión traqueal ${ }^{1,3,4}$. Algunos describen hemorragia digestiva alta por ulceración del extremo distal. Existen reportes de casos de asfixia por impactación del pólipo móvil hacia la vía aérea superior ${ }^{5}$.

En el estudio radiológico baritado aparece como una masa expansiva, lisa, con forma de "salchicha".

En la tomografía computada la masa intraluminal presenta distintos grados de atenuación dependiendo de la proporción de contenido adiposo y fibroso, y puede ser homogéneo o heterogéneo.
El tratamiento habitualmente es la resección por vía clásica por esofagostomía o, como en este caso, por vía endoscópica.

\section{Referencias}

1. Kim TS, Song SY, Han J, Shim YM, Jeong HS. Giant fibrovascular polyp of the esophagus: CT findings. Abdom Imaging 2005; 30: 653-5.

2. Ascenti G, Racchiusa S, Mazziotti S, Bottari M, Scribano E. Giant fibrovascular polyp of the esophagus: CT and MR findings. Abdom Imaging 1999; 24: 109-10.

3. Levine MS, Buck JL, Pantongrag-Brown L, Buetow PC, Hallman JR, Sobin LH. Fibrovascular Polyps of the Esophagus: Clinical, Radiographic, and Pathologic Findings in 16 Patients. AJR 1996; 166: 781-7.

4. Dutta R, Kumar A, Handa KK, Dinda AK. Large pedunculated fibrovascular polyp of oesophagus in a young woman. Interact Cardiovasc Thorac Surg 2009; 9: 352-3.

5. Alobid I, Vilaseca I, Fernández J, Bordas JM. Giant fibrovascular polyp of the esophagus causing sudden dyspnea: endoscopic treatment. Laryngoscope 2007; 117: 944-5. 